\title{
Electroconvulsive therapy in delusional and non-delusional depressive disorder *
}

\author{
Atul C. Pande ${ }^{1,2,3}$, Leon J. Grunhaus ${ }^{1,2,3}$, Roger F. Haskett ${ }^{1,3}$ and John F. Greden ${ }^{3}$ \\ ${ }^{\prime}$ Depression Program and ${ }^{2}$ Electroconvulsive Therapy Program, ${ }^{3}$ Department of Psychiatry, University of Michigan Medical Center, \\ Ann Arbor, MI 48109-0118, U.S.A.
}

(Received 26 September 1989)

(Accepted 25 January 1990)

\section{Summary}

Major depressive disorder (MDD) patients $(n=66)$ treated with electroconvulsive therapy were stratified by the presence $(n=30)$ or absence $(n=36)$ of delusional symptoms (by Research Diagnostic Criteria) to compare their response to treatment. At discharge from hospital $83 \%$ of the MDD with psychosis group and 58\% of the MDD without psychosis group were good responders $(P=0.03)$. The implications of this are discussed.

Key words: Electroconvulsive therapy; Delusional depression; Major depression; Psychotic depression; Predictors of response

\section{Introduction}

In an earlier study of the predictors of response to electroconvulsive therapy (ECT) (Pande et al., 1988) we confirmed the suggestion (Abrams, 1982) that a diagnosis of major depressive disorder (MDD) of at least moderate severity leaves insufficient variability in the symptom picture to allow

Address for correspondence: Atul C. Pande, MD, Department of Psychiatry, D9702 UH, Box 0118, University of Michigan Medical Center, 1500 East Medical Center Drive, Ann Arbor, MI 48109-0118, U.S.A.

\footnotetext{
* Presented as a poster at the Society of Biological Psychiatry Annual Meeting, San Francisco, CA, May 1989.
}

identification of clinical features predictive of a differential treatment response. Even delusional symptoms were not found in our study to be a predictor of response which is contrary to the earlier literature (Crow and Johnstone, 1986) supporting the presence of psychosis as a favorable predictor of ECT response. Since formalized diagnostic systems have come into greater clinical use, two small studies (Rich et al., 1986; Solan et al., 1988) comparing ECT response rates between delusional depression and non-delusional depression have reported no differences. Rich et al. studied 30 depressed patients (nine delusional and 21 non-delusional) and found equal rates of response. Solan et al. reviewed 46 pharmacotherapyresistant depressives who received ECT and found that delusionals and non-delusionals responded 
equally well. Among the delusional depressives, response to ECT was affected by the type of delusions. Patients with nihilistic delusions did better than those with paranoid delusions.

Since, at least on a phenomenologic basis, the distinction between delusional and non-delusional depression secms rather clear, wc werc prompted to re-examine the question of differential response to FCT in a sample larger than our previous study. Furthermore we examined the effect of electrode placement on the response to ECT in the two groups of subjects as well since it has been suggested that it is preferable to treat delusional MDD with bilateral ECT (Abrams, 1988) despite the risk of more cognitive impairment.

\section{Method}

The sample was drawn from the database of the Depression Program of the University of Michigan Medical Center. Diagnosis by the Research Diagnostic Criteria (RDC; Spitzer et al., 1978), clinical ratings and ECT parameters (machine, energy settings, seizure duration, etc.) are routinely collected on patients treated with ECT and are entered into the computerized database. Diagnostic data are obtained through a structured interview - the Schedule for Affective Disorders and Schizophrenia (SADS) - and/or by clinical interviews by at least two clinicians who use the RDC rules to reach a consensus diagnosis. This also includes consensus on the presence or absence of psychotic and endogenous RDC subtypes. Clinical ratings consist of the Hamilton Rating Scale for Depression (HRSD) and the Global Assessment Scale (GAS) which are conducted by the primary clinicians and are, therefore, not 'blind' to the treatment status. The Depression Program periodically conducts interrater reliability training sessions for all clinicians to ensure consistency of ratings.

The present sample is a subset of the above database and consisted of 66 inpatients (including 48 subjects already reported on by Pande et al., 1988) with a diagnosis of major depressive disorder by the RDC and treated with ECT through the Electroconvulsive Therapy Program of the University of Michigan Medical Center. Only those patients who required at least five ECTs in a course of treatment were included. Thirty patients had psychotic symptoms by RDC and 36 did not. Clinical status was rated prior to commencement of ECT on the 17-item HRSD (Hamilton, 1960) and this rating was repeated within a week of ending ECT and at the time of discharge from the hospital. The Global Assessment Scale (GAS) was also collected before and after ECT.

A sine wave MFDCRAFT or a pulse wave MECTA SR-2 machine was used to give ECT three times a week following patient screening with routine laboratory tests, spinal films, electrocardiogram, and specialist consultation with cardiology and anesthesia. Glycopyrrolate $0.1-0.2$ $\mathrm{mg}$ i.m. was used as premedication when indicated. Anesthesia was induced with methohexital $1 \mathrm{mg} / \mathrm{kg}$ body weight and muscle relaxation with succinylcholine $0.75 \mathrm{mg} / \mathrm{kg}$ body weight. Voltage and duration, electrode placement (unilateral d'Elia or bitemporal), and total number of treatments given were determined by the primary clinician. Generally, the settings for the MEDCRAFT machine were $100-160 \mathrm{~V}$ and $0.5-1.0 \mathrm{~s}$, while for the MECTA the energy levels ranged between 30 and $90 \mathrm{~J}$. The machines were adjusted to achieve a seizure duration (monitored by the 'cuff method') of $25 \mathrm{~s}$ or more. Shorter seizures were followed by re-stimulation at a higher energy level. Total number of treatments ranged between 5 and 17 (mean $\pm \mathrm{SD}=9.3 \pm 2.4$ ). No formal attempt was made to control the end point of ECT which followed clinical judgements.

\section{Results}

The demographic and clinical variables of the two subgroups are shown in Table 1. The sex distribution was similar in the subgroups but the delusional MDD patients were significantly younger $(P<0.02)$ although neither the age of onset of the first depressive episode nor the number of previous episodes was different between the groups. The delusionals had a significantly shorter hospital stay $(P<0.04)$ but this was accounted for by the non-delusionals having been in hospital longer before $(P<0.005)$ the start of ECT. Hospital stay after the first ECT was identical for both groups. 
TABLE 1

SAMPLE CHARACTERISTICS AND ECT PARAMETERS

\begin{tabular}{|c|c|c|}
\hline & $\begin{array}{l}\text { MDD - } \\
\text { delusional } \\
(n=30)\end{array}$ & $\begin{array}{l}\text { MDD - non- } \\
\text { delusional } \\
(n=36)\end{array}$ \\
\hline $\operatorname{Sex}(M: F)$ & $8: 22$ & $11: 25$ \\
\hline \multicolumn{3}{|l|}{ Age } \\
\hline At first episode & $44.2 \pm 19.9$ & $47.0 \pm 18.2$ \\
\hline At present & $58.3 \pm 14.9$ & $65.9 \pm 10.8$ \\
\hline Number of episodes & $2.1 \pm \quad 2.7$ & $3.1 \pm 2.9$ \\
\hline Length of hospital stay & $64.0 \pm 25$ & $80.0 \pm 33$ \\
\hline Before first $\mathrm{ECT}{ }^{b}$ & $15.2 \pm 12.9$ & $31.4 \pm 27.3$ \\
\hline After first ECT & $48.5 \pm 25.2$ & $48.5 \pm 16.9$ \\
\hline \multicolumn{3}{|l|}{ Electrode placement } \\
\hline Unilateral (UL) & 17 & 18 \\
\hline Bilateral (BL) & 11 & 11 \\
\hline \multicolumn{3}{|l|}{ Switched (SW) } \\
\hline (UL to BL) & 2 & 7 \\
\hline Number of ECTs & $8.9 \pm 2.9$ & $9.5 \pm 2.1$ \\
\hline $\begin{array}{l}\text { Total seizure duration } \\
\quad(\text { mean } \pm \mathrm{SD}, \mathrm{s})\end{array}$ & $407.3 \pm 208.9$ & $415.2 \pm 176.9$ \\
\hline
\end{tabular}

The mean number of ECTs and the cumulative seizure duration for the course of ECT did not differ, suggesting that both groups received equal amounts of treatment. Electrode placement, categorized as bilateral (BL), unilateral (UL) and unilateral to bilateral switch (SW), did not differ significantly between the delusional and non-delusional groups. Number of treatments between UL and $\mathrm{BL}+\mathrm{SW}$ did not differ $(9.5 \pm 2.9$ vs. $9.2 \pm 2.4$, $t=0.49, P=\mathrm{NS})$ in the total sample. In the nondelusional group, the UL patients received $8.7 \pm$ 2.1 ECTs versus $10.2 \pm 2.0$ in the $\mathrm{BL}+\mathrm{SW}(P<$ 0.05 ) but the difference was not significant when the two paticnts who reccived 14 ECTs (i.e., more than 2 standard deviations above the mean ECTs for the sample) were excluded from the $\mathrm{BL}+\mathrm{SW}$ group. Similarly, in the delusional group, the UL patients received $10.3 \pm 3.4$ ECTs against $7.6 \pm 2.1$ in the $\mathrm{BL}+\mathrm{SW}$. This difference was significant $(P<0.05)$ but when the UL patients who received over 14 ECTs were excluded, there was no statistical difference.

Baseline, i.e., pre-ECT, mean HRSD scores were similar in the groups (Table 2) but a repeated measures ANOVA for the mean HRSD scores pre ECT, post ECT and at discharge grouped by the delusional-non-delusional distinction showed a significant group by time interaction in favor of the delusional MDD group. Similarly the repeated measures ANOVA for the mean GAS scores pre ECT and post ECT revealed a significant group by time interaction. The total HRSD scores were used to categorize patients as responders or nonresponders based on a total 17-item HRSD of 10 points. Good responders (defined as an HRSD of 10 or less) as compared to poor responders $($ HRSD $\geq 11)$ had a greater mean decrease in HRSD score at the post-ECT (75\% vs. $44 \%, t=5.5$, $P=0.0001)$ as well as the discharge (78\% vs. $50 \%$, $t=7.5, P=0.0001$ ) ratings. The post-ECT rate of good treatment response was higher in the delusional $(21 / 30,70 \%)$ than the non-delusional group $(17 / 36,47 \%)\left(\chi^{2}=3.5, d f=1, P=0.06\right)$. This significant trend became stronger at the time of discharge when $25 / 30$ (83\%) delusional and 21/36 (58\%) non-delusional patients were categorized as responders $\left(\chi^{2}=4.84, d f=1, P=0.03\right)$. Since it was possible that the non-delusionals may have included an excess of non-endogenous depressives, we cross-categorized the endogenous and psychotic RDC subtypes. Of the delusional MDD group $28 / 30(93 \%)$ met the endogenous subtype as compared to $30 / 36(83 \%)$ of the non-delusional group $\left(\chi^{2}=1.5, d f=1, \mathrm{NS}\right)$. Thus, poorer response in

TABLE 2

PSYCHOSIS AND RESPONSE TO ECT

\begin{tabular}{|c|c|c|}
\hline & $\begin{array}{l}\text { MDD - } \\
\text { delusional } \\
(n=30)\end{array}$ & $\begin{array}{l}\text { MDD - non- } \\
\text { delusional } \\
(n=36)\end{array}$ \\
\hline \multicolumn{3}{|c|}{$\overline{\mathrm{HRSD}(\operatorname{mean} \pm \mathrm{SD})^{\mathrm{a}}}$} \\
\hline Pre ECT & $28.4 \pm 6.3$ & $26.5 \pm 6.0$ \\
\hline Post ECT & $9.5 \pm 6.7$ & $11.1 \pm 6.4$ \\
\hline At discharge & $7.5 \pm 6.4$ & $9.3 \pm 5.7$ \\
\hline \multicolumn{3}{|c|}{ GAS $(\text { mean } \pm S D)^{b}$} \\
\hline Pre ECT & $30.5 \pm 9.9$ & $37.4 \pm 12.9$ \\
\hline Post ECT & $60.8 \pm 16.9$ & $56.4 \pm 20.8$ \\
\hline \multicolumn{3}{|c|}{ Response rate (patients with $H R S D \leq 10$ ) } \\
\hline Post ECT ${ }^{c}$ & $21 / 30(70 \%)$ & $17 / 36(47 \%)$ \\
\hline At discharge ${ }^{d}$ & $25 / 30(83 \%)$ & $21 / 36(58 \%)$ \\
\hline
\end{tabular}

${ }^{a}$ Repeated measures ANOVA, $F=4.21, d f=2, P<0.02$.

b Repeated measures ANOVA, $F=5.98, d f=1, P<0.02$.

${ }^{2}=3.5 . d f=1, P=0.06$.

d $\chi^{2}=4.84, d f=1, P=0.03$. 
TABLE 3

PSYCHOSIS, ELECTRODE PLACEMENT AND RESPONSE TO ECT

\begin{tabular}{|c|c|c|c|c|c|c|}
\hline & \multicolumn{3}{|c|}{ MDD - delusional } & \multicolumn{3}{|c|}{ MDD - non-delusional } \\
\hline & $\begin{array}{l}\mathrm{UL} \\
(n=17)\end{array}$ & $\begin{array}{l}\text { BL } \\
(n=11)\end{array}$ & $\begin{array}{l}\text { SW } \\
(n=2)\end{array}$ & $\begin{array}{l}\mathrm{UL} \\
(n=18)\end{array}$ & $\begin{array}{l}\mathrm{BL} \\
(n=11)\end{array}$ & $\begin{array}{l}\text { SW } \\
(n=7)\end{array}$ \\
\hline Post ECT & $\begin{array}{l}9 \\
(53 \%)\end{array}$ & $\begin{array}{l}11 \\
(100 \%)\end{array}$ & $\begin{array}{l}1 \\
(50 \%)\end{array}$ & $\begin{array}{l}6 \\
(33 \%)\end{array}$ & $\begin{array}{l}8 \\
(73 \%)\end{array}$ & $\begin{array}{l}3 \\
(43 \%)\end{array}$ \\
\hline At discharge & $\begin{array}{l}13 \\
(76 \%)\end{array}$ & $\begin{array}{l}11 \\
(100 \%)\end{array}$ & $\begin{array}{l}1 \\
(50 \%)\end{array}$ & $\begin{array}{l}8 \\
(44 \%)\end{array}$ & $\begin{array}{l}9 \\
(82 \%)\end{array}$ & $\begin{array}{l}4 \\
(57 \%)\end{array}$ \\
\hline
\end{tabular}

All NS.

the non-delusionals could not be attributed to the lack of 'endogenous' features.

At the post-ECT rating 23 of 31 (74\%) patients treated with bilateral ECT or switched from unilateral to bilateral ECT were responders as compared to 15 of 35 (43\%) treated with unilateral ECT $\left(\chi^{2}=6.61, d f=1, P=0.01\right)$. The difference was not as significant at the time of discharge when $25 / 31(81 \%)$ bilaterals and switched were responders as compared to $21 / 35(60 \%)$ unilaterals. Table 3 shows the rates of response in the delusional and non-delusional groups stratified by the electrode placement. Although delusionals receiving bilateral ECT were more likely to be responders the differences were not statistically significant.

\section{Discussion}

This study found that in depressed inpatients with a comparable severity of illness prior to treatment, there was a significant trend toward the delusional depressives having a higher rate of response than non-delusional depressives with ECT at the end of treatment. This difference became statistically significant at the time of discharge. It has been suggested that bilateral ECT may be preferable in delusional MDD (Abrams, 1988), hence we examined whether electrode placement affected response. The frequency with which unilateral and bilateral electrode placement was used in the delusional and non-delusional groups was similar. Overall, bilateral ECT was significantly more likely to be associated with a response at the end of ECT than unilateral ECT. This difference was not significant at discharge and may indicate that the electrode placement influences the speed of response. All of the delusional depressives treated with bilateral ECT were responders at the end of treatment and at discharge whereas among those treated with unilateral ECT only half were responders post ECT and about three-quarters at discharge. These differences failed to reach statistical significance. In the non-delusional patients as well treatment response was better in those receiving bilateral ECT but the difference was not as great as in the delusional MDD patients. The efficacy of bilateral ECT was not significantly different between the delusional and non-delusional groups, nor was the efficacy of unilateral ECT different between the groups.

The demographic and treatment response differences between the delusional and non-delusional depressives suggest that they may represent overlapping but distinct populations, which arrive at ECT for different reasons. As there were no significant differences in the pretreatment severity of depression, it is possible that delusional depression may not be just a more severe form of depressive illness on a continuum with non-delusional depression. This possibility deserves further study. The clinical selection process as a source of bias also needs to be considered in that while the delusional depressives may receive ECT as a treatment of first choice, the non-delusional depressives often arrive at ECT after having failed to respond to pharmacotherapy. This would account for the longer hospital stay and may mean that this group represents a more chronic or treatmentrefractory form of depressive illness. We could not analyze our sample to identify how many may have been referred for refractory depression as 
opposed to those who received ECT because they were severely ill. We believe such analysis in future prospective studies would be valuable.

Despite the retrospective nature of this study, the findings provide further encouragement to conduct prospective studies using random assignment of delusional and non-delusional depressives to unilateral and bilateral ECT so as to elucidate the role of delusional symptoms and electrode placement in the response to ECT.

\section{Acknowledgements}

Supported in part by NIMH Grant RO1 MH40216 and the University of Michigan Department of Psychiatry.

\section{References}

Abrams, R. (1982) Clinical prediction of ECT response in depressed patients. Psychopharm. Bull. 18, 48-50.

Abrams, R. (1988) Electroconvulsive Therapy. Oxford University Press, New York, NY.

Crow, T.J. and Johnstone, E.C. (1986) Controlled trials of electroconvulsive therapy. Ann. N.Y. Acad. Sci. 462, 12-29.

Hamilton, M. (1960) A rating scale for depression. J. Neurol. Neurosurg. Psychiatry 23, 56-62.

Pande, A.C., Krugler, T., Haskett, R.F., Greden, J.F. and Grunhaus, L.J. (1988) Predictors of response to electroconvulsive therapy in major depressive disorder. Biol. Psychiatry 24, 91-93.

Rich, C.L., Spiker, D.G., Jewell, S.W., Neil, J.F. and Phillipson, M. (1986) ECT response in psychotic versus non-psychotic unipolar depressives. J. Clin. Psychiatry 47, 123-125.

Solan, W.J., Khan, A., Avery, D.H. and Cohen, S. (1988) Psychotic and non-psychotic depression: comparison of response to ECT. J. Clin. Psychiatry 49, 97-99.

Spitzer, R.L., Endicott, J. and Robins, E. (1978) Research Diagnostic Criteria: rationale and reliability. Arch. Gen. Psychiatry 35, 773-782. 